\title{
OPTIMAL EXPANSION OF WATER QUALITY MONITORING NETWORK BY FUZZY OPTIMIZATION APPROACH
}

\author{
SHU-KUANG NING ${ }^{1 *}$ and NI-BIN CHANG ${ }^{2}$ \\ ${ }^{1}$ Department of Environmental Engineering, Kun-Shan University of Technology, Tainan, Taiwan, \\ R.O.C.; ${ }^{2}$ Department of Environmental Engineering, Texas A\&M University, Kingsville, Texas, \\ U.S.A. \\ (* author for correspondence, e-mail: ning@mail.ksut.edu.tw)
}

(Received 25 July 2002; accepted 6 February 2003)

\begin{abstract}
River reaches are frequently classified with respect to various mode of water utilization depending on the quantity and quality of water resources available at different location. Monitoring of water quality in a river system must collect both temporal and spatial information for comparison with respect to the preferred situation of a water body based on different scenarios. Designing a technically sound monitoring network, however, needs to identify a suite of significant planning objectives and consider a series of inherent limitations simultaneously. It would rely on applying an advanced systems analysis technique via an integrated simulation-optimization approach to meet the ultimate goal. This article presents an optimal expansion strategy of water quality monitoring stations for fulfilling a long-term monitoring mission under an uncertain environment. The planning objectives considered in this analysis are to increase the protection degree in the proximity of the river system with higher population density, to enhance the detection capability for lower compliance areas, to promote the detection sensitivity by better deployment and installation of monitoring stations, to reflect the levels of utilization potential of water body at different locations, and to monitor the essential water quality in the upper stream areas of all water intakes. The constraint set contains the limitations of budget, equity implication, and the detection sensitivity in the water environment. A fuzzy multi-objective evaluation framework that reflects the uncertainty embedded in decision making is designed for postulating and analyzing the underlying principles of optimal expansion strategy of monitoring network. The case study being organized in South Taiwan demonstrates a set of more robust and flexible expansion alternatives in terms of spatial priority. Such an approach uniquely indicates the preference order of each candidate site to be expanded step-wise whenever the budget limitation is sensitive in the government agencies.
\end{abstract}

Keywords: environmental systems analysis, fuzzy multi-objective programming, monitoring network, river basin planning, water quality management

\section{Notation}

The following symbols are used in this article:

$\mu_{Z_{i}}=$ the aspiration level corresponding to the $i$ th fuzzy objective;

$C_{i j k}=$ the mean concentration of the $k$ th pollutant of concern in the dry season at the $j$ th monitoring station in the $i$ th tributary $\left(\mathrm{mg} \mathrm{L}^{-1}\right)$;

$D_{i j}=$ the distance between the $j$ th monitoring station located at the $i$ th tributary and the reference point of estuary location $(\mathrm{km})$; 
$E_{i j}=$ the distance between the $j$ th monitoring station located at the $i$ th tributary and the nearest potable water intake in the upper stream area $(\mathrm{km})$;

$L_{c}=$ allowable overlapped half-life distance in this systems analysis $(\mathrm{km})$;

$L_{i}=$ the lower bound of tolerance interval in the $i$ th fuzzy membership function;

$L_{i j k}=$ the distance required for a decay of half concentration of the $k$ th pollutant where the $j$ th monitoring station in the $i$ th tributary is located $(\mathrm{km})$;

$M \quad$ = the upper bound of the number of monitoring stations (no unit);

$p=$ the number of tributary in Kao-Ping River basin;

$P_{i j}=$ the population covered within the $10 \mathrm{~km}$ in radius where the $j$ th monitoring station in the $i$ th tributary is located (capita);

$q_{i}=$ the total number of candidate station in the $i$ th tributary;

$r \quad=$ the total number of pollutants of concern;

$R_{i j}=$ the utilization category of a water body in the river reach where the $j$ th monitoring station in the $i$ th tributary is located (no unit);

$S_{i j k}=$ the water quality standard of the $k$ th pollutant in the river reach of concern where the $j$ th monitoring station in the $i$ th tributary is located $\left(\mathrm{mg} \mathrm{L}^{-1}\right)$;

$U_{i}=$ the upper bound of tolerance interval in the $i$ th fuzzy membership function;

$Y_{i j}=$ the binary variable in which 1 represents that the candidate location is included in the alternative, 0 otherwise (no unit).

\section{Introduction}

In the last centaury, the impact of changing land use patterns continuously poses stress on all types of water bodies, including those beneath the ground. Water quality monitoring efforts are thus aimed at determining the condition of entire watersheds - the area drained by rivers, groundwater aquifer, lakes, and estuaries. Surface water quality monitoring is of significance in the line of duty to support terrestrial ecosystem. It can be conducted at regular sites on a continuous basis, at selected sites on a temporary or seasonal basis for an intensive survey, or at spontaneous site on an emergency basis after an illegal spill. Monitoring of water quality using regular sites on a continuous basis must collect both temporal and spatial information for comparison with respect to the preferred condition of a water body (i.e., mode of water utilization). To reflect the needs of water on watershed-based activities, river reaches are frequently classified with respect to various modes of water utilization depending on the quantity and quality of water resources available 
at different locations. The constituents to be monitored in water may include levels of dissolved oxygen, biochemical oxygen demand, temperature, $\mathrm{pH}$, conductivity, turbidity, total suspended solids, fecal coliform bacteria, ammonia, nitrate plus nitrite, total nitrogen, total phosphorus, soluble reactive phosphorus, metals, oils, pesticides, and even fish tissue.

The design issues related to surface water quality monitoring network have received wide attention since 1970s (Moore, 1973; Beckers and Chamberlain, 1974; Lettenmaier, 1978; Ward, 1979). Various attempts were made in the 80s to improve the monitoring efficiency with regard to the basic design criteria (Skalski and Mackenzie, 1982), optimization analysis (Groot and Schilperoot, 1983), comparing the features of fixed stations versus intensive surveys (Van Belle and Hughes, 1983), the consolidation of the network design (Lettenmaier et al., 1984), the importance of data collection (Whitfeld, 1988), and the interpretation of monitoring outcome (Ellis, 1989). Earlier studies in the 1990s focused on fundamental principles and applications in siting the water quality monitoring stations (Smith and McBride, 1990; Loftis et al., 1991; Esterby et al., 1992). Later on, in an attempt to assess systematic issues relevant to network design, more studies applied the techniques of integer programming (Hudak et al., 1995), statistical assessment (Hussain et al., 1995), multi-objective programming (Harmancioglu and Alpaslan, 1992; Cieniawski et al., 1995), and Kriging theory (Lo et al., 1996). A broader sense of applications was gained from the discussions of design principles of monitoring network (Dixon and Chiswell, 1996) and the guidelines related to biological impact assessment in the rivers (Timmerman et al., 1997). On the other hand, ground water monitoring network design was viewed as an intimate issue linked with surface water monitoring network design. Comparative study and extension work were also conducted (Claessen, 1997; Sprull and Candela, 1990; and Loaiciga et al., 1992). To account for the uncertainty in decision analysis, optimization analyses for incorporating risk and uncertainty in various water quality and air quality monitoring programs were performed based on probability theory (Feiring et al., 1998), fuzzy sets theory (Bogardi et al., 1983; Kindler et al., 1992; Lee et al., 1994; Wu et al., 1997; Chang et al., 1997; Chen and Chang, 1998), and grey systems theory (Chang et al., 1996a, b; Chang and Tseng, 1999).

The goal of this study is to present an optimal expansion strategy of water quality monitoring stations in a river system via an integrated simulation-optimization procedure. In view of the inherent complexity of integrating simulation outputs at various scales for building the optimization steps and searching for the ultimate solutions, a set of coefficients with regard to half-life distance accounting for the systematic trait of pollutant transport and transformation are derived to bridge the application gap. The planning objectives considered are to increase the protection degree in the proximity of river system with higher population density, to enhance the detection capability for those lower compliance areas, to promote the detection sensitivity by better deployment and installation of monitoring stations, to reflect the levels of utilization potential of water body at different locations, 
and to monitor the essential water quality in the upper stream areas of all water intakes. The constraint set contains the limitations of budget, equity implication, and the detection sensitivity in the water environment. To reflect the uncertainties in decision-making and postulate the underlying principles of fuzzy decision analysis, fuzzy expressions were used for illustrating the planning objectives in the context of traditional multi-objective programming framework. The case study demonstrates a fuzzy multi-objective evaluation framework that was applied for analyzing, screening, and sequencing the expansion alternatives in connection to basin-wide water quality monitoring stations. This will lead to provide a more robust and flexible optimal expansion strategy in South Taiwan.

\section{Analytical Methodology}

Monitoring network design can be conducted for many purposes. They include: (1) characterizing changes or trends in water quality over time, (2) identifying specific existing or emerging water quality problems, (3) gathering information to design specific pollution prevention or remediation programs, (4) determining whether program goals - such as compliance with pollution regulations or implementation of effective pollution control actions - are being met, and (5) responding to emergencies, such as spills and floods (U.S. EPA, 2002). Some types of monitoring activities meet several of these purposes at the same time; others are specifically designed for simply meeting one purpose. However, water quality monitoring network design historically have tend to use experience, intuition, and subjective judgment in siting monitoring stations. This often results in a longterm or short-term sampling program that is not consensus-oriented, risk-informed, scientifically credible, and cost-effective. It is therefore worthwhile to reexamine such a traditional environmental problem via the use of advanced systems analysis techniques that are deemed critical for environmental decision-making in highly collaborative nature of the information-based endeavors.

To meet this study goal, it would require involving a two-stage analysis using integrated simulation-optimization modeling. First of all, sampling campaigns must be performed and a simulation model, such as QUAL2E or WASP models, has to be fully calibrated, verified, and applied for retrieving the essential information of environmental assimilative capacity along the river reaches and the water quality levels at these spots where there is no monitoring records. This could help aid in assessing the potential associated with each monitoring site in the optimization analysis. Then, the second stage analysis requires implementing a multi-objective evaluation analysis to search for the optimal expansion strategy with respect to multi-constitutes impacts. Four constitutes, including dissolved oxygen (DO), Biochemical Oxygen Demand (BOD), total phosphorus (TP), and ammonia-nitrogen $\left(\mathrm{NH}_{3}-\mathrm{N}\right)$, were considered in this study although another more may be included 


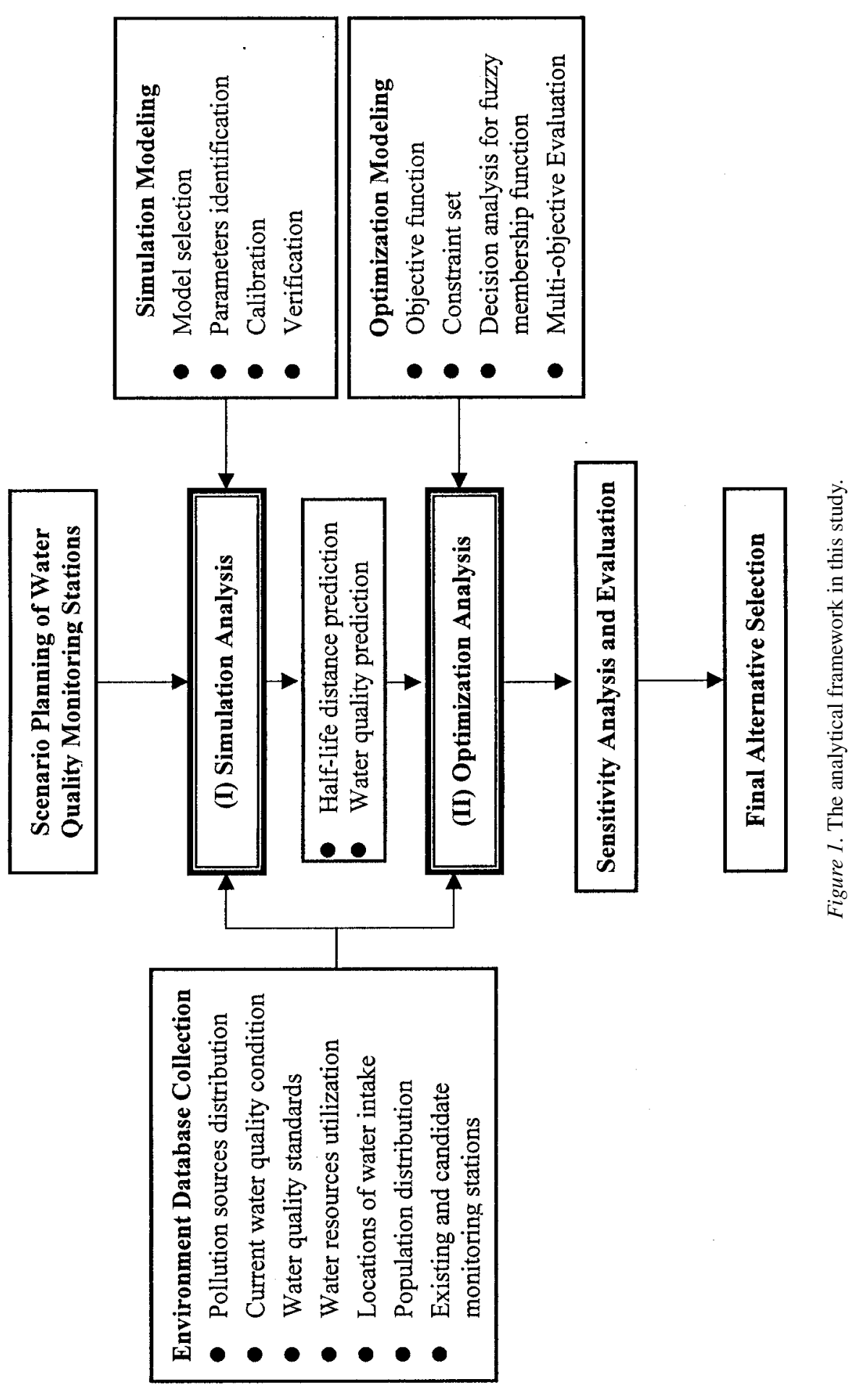


as well. Figure 1 indicates the analytical framework applied in this study. Detail principles and procedures are explained as follows:

\subsection{STAGE I: WATER QUALITY SIMULATION MODEL}

Simulation analysis is deemed as an integral part of a complete monitoring program design (Ning et al., 2001). The simulation outputs that characterized the internal features of assimilative capacity in a river system will then provide clues of site potential and will largely dictate the later site-selection process in the optimization framework. The simulation model of QUAL2E, which was used as a simulation tool in this study, is basically a steady-state model for tracing conventional pollutants in one-dimensional streams and well-mixed ecosystems (Brown and Barnwell, 1987). This simulation model illustrates the important physical, biological and chemical processes and their interactions for the particular water quality constitutes of interest based on a set of partial differential equations. The governing equations of QUAL2E illustrate the effects of dispersion, advection, constituent reactions, and interactions among constitutes. It allows multiple waste discharges, withdrawals, tributary flows, and incremental inflow and outflow. QUAL2E may consider up to fifteen constitutes mainly including conservative mineral (C), algae (A), ammonia-nitrogen $\left(\mathrm{NH}_{3}-\mathrm{N}\right)$, nitrite-nitrogen $\left(\mathrm{NO}_{2}-\mathrm{N}\right)$, nitrate-nitrogen $\left(\mathrm{NO}_{3}-\mathrm{N}\right)$, phosphate-phosphorus (P), biochemical oxygen demand (BOD), dissolved oxygen $(\mathrm{DO})$, coliform $(\mathrm{F})$, and radioactive material $(\mathrm{R})$. But this analysis is designed to be capable of predicting the variations of DO and the decay rate of BOD, TP, and $\mathrm{NH}_{3}-\mathrm{N}$ along the river reaches.

The simulation model of QUAL2E is applicable to describe the water quality situation in dendritic streams. It assumes that the major transport mechanisms, advection and dispersion are significant only alone the main direction of flow and the water body is well mixed in the cross section. While the hydraulic system is described by a set of relatively rough regression equations, the pollutant transport and transformation is designed based on fairly complex processes. In Taiwan, the river channel is quit shallow and steep rendering higher flow velocity in most reaches. Hence, the assumption of well mixing in the cross section can be acceptable as long as the size of each grid being designed in the computation framework is limited to some extent.

The simulation model (i.e., QUAL2E) was used to estimate two types of information for optimization analysis in this study: (1) the half-life distance $\left(L_{i j k}\right.$ in Equation (3)) that is a geographical distance with a scale of ten to twenty kilometers; (2) the possible water quality levels predicted at each candidate location where there is no any prior monitoring records. This information is addressed based on such a basin-wide modeling framework with a scale of several hundreds kilometers in general. But grid used in computational framework may account for the water quality situation covering an area from half kilometer to one kilometer along the river reach. However, the distance between any adjacent monitoring stations in the 
river system of concern is much larger than the longitudinal length of any single grid in the computational framework. Therefore, there was no scale-matching problem between the simulation and optimization models in this study for the grid system was well designed to avoid such issue.

\subsection{Stage II: FuZZy multi-ObJeCtive PROgRAmming ANALysis}

The systems analysis approach applied for expanding the monitoring network in this article require considering several significant planning objectives. They are designed to increase the protection degree in the proximity of the river system with higher population density, to enhance the detection capability for those lower compliance areas, to promote the potential detection sensitivity by better installation and deployment, to reflect the levels of utilization potential of water body at different locations, and to monitor the essential water quality in the upper stream areas of all water intakes. The constraint set contains the limitations of budget, equity implication, protection of water intakes, and the detection sensitivity in the water environment. To address the uncertainty in decision-making, it eventually leads to employ a fuzzy multi-objective mixed integer-programming model to perform effective screening, siting, and scheduling for those candidate sites. Since the difference of stream flow rate between the wet and dry seasons is phenomenal in many river basins, only the scenario in the dry season needs to be concerned in the planning and design stage.

\subsubsection{Objective Function}

1. Maximization for enhancing the detection capability for those lower compliance areas: The proposed methodology for designing an effective water quality monitoring system first aims at compliance monitoring, that is, for detecting violations of regulations. Thus, this objective indicates the monitoring network to be built or expanded should exhibit the highest potential capability to detect the severely polluted areas with respect to a set of pollutants of concern. It can be expressed as:

$$
Z_{1}=\sum_{i=1}^{p} \sum_{j=1}^{q_{i}} Y_{i j} \sum_{k=1}^{r} \frac{C_{i j k}-S_{i j k}}{C_{i j k}}, \quad \forall i, j, k,
$$

in which $C_{i j k}$ represents the mean concentration of the $k$ th pollutant of concern in the dry season at the $j$ th monitoring station in the $i$ th tributary $\left(\mathrm{mg} \mathrm{L}^{-1}\right) ; S_{i j k}$ is the water quality standard of the $k$ th pollutant in the river reach of concern where the $j$ th monitoring station in the $i$ th tributary is located $\left(\mathrm{mg} \mathrm{L}^{-1}\right) ; p$ is the total number of tributary in a river basin; $q_{i}$ is the total number of candidate station in the $i$ th tributary; $r$ is the total number of pollutant of concern (no unit); and $Y_{i j}$ is the binary variable in which 1 represents that the candidate location is included in the alternative, 0 otherwise (no unit). 
2. Maximization for reflecting the levels of utilization potential of a water body at different locations: This objective implies that the higher the utilization potential of a water body in the river reach, the more the motivation to site the monitoring station(s).

$$
Z_{2}=\sum_{i=1}^{p} \sum_{j=1}^{q_{i}} Y_{i j} R_{i j}, \quad \forall i, j,
$$

in which $R_{i j}$ is the corresponding weighting factor associated with a mode of water body utilization in the river reach where the $j$ th monitoring station in the $i$ th tributary is located (no unit). The value of R might be set up between 0 and 1 (i.e., $1.0,0.8,0.6,0.4$, and 0.2 for each mode of utilization from A to $\mathrm{E}$, respectively, as they are frequently applied in many countries).

3. Maximization for promoting the detection sensitivity by better deployment and installation: This objective shows that siting of monitoring stations in a river system must take the situation of pollutant transport and transformation into account. This is because the need for siting is deemed highly relevant to the local environmental assimilative capacity. Such a design criteria emphasizes that an optimal monitoring network should be spatially located for leading to increase its overall detection sensitivity or alarming potential with respect to a set of pollutants of concern in a river system. Thus, a new parameter - the half-life distance - should be defined in advance according to the outputs from simulation model. The longer the halflife distance for a pollutant in the proximity of a specific candidate site, the less the chance for a neighboring candidate site to be selected into a siting alternative. Using derived half-life distance may present high potential for exhibiting, eliciting, and summarizing the non-linear behavior pollutant transport and transformation in a natural system for supporting complex optimization analysis. However, an integrated index related to all constitutes of concern via a weighted summation of several half-life distances is required to facilitate gaining a comprehensive understanding of the overall environmental assimilative capacity in a river system. The following formulation must be functioned along with the third constraint (i.e., Equation (13)) to form an integrative screening capability.

$$
Z_{3}=\sum_{i=1}^{p} \sum_{j=1}^{q_{i}} Y_{i j} \sum_{k=1}^{r} L_{i j k}, \quad \forall i, j, k,
$$

in which $L_{i j k}$ is the half-life distance that is the geographical distance required for a decay of half concentration of the $k$ th pollutant where the $j$ th monitoring station in the $i$ th tributary is located (km).

4. Maximization for increasing the protection degree in the proximity of the river system with higher population density: This objective illustrates the purpose that 
monitoring stations should be sited as close as possible to the locations where most population are resided along the river reaches.

$$
Z_{4}=\sum_{i=1}^{p} \sum_{j=1}^{q_{i}} Y_{i j} P_{i j}, \quad \forall i, j,
$$

in which $P_{i j}$ is the population covered within the radius of $10 \mathrm{~km}$ where the $j$ th monitoring station in the $i$ th tributary is located in the proximity of this region (capita).

5. Maximization for increasing the monitoring potential in the upper stream areas of all water intakes: This objective implies that monitoring stations should be sited as close as possible to the upper stream locations of all water intakes.

$$
Z_{5}=\sum_{i=1}^{p} \sum_{j \in S} Y_{i j} \frac{1}{E_{i j}}, \quad \forall i, \quad \forall j \in S,
$$

in which $E_{i j}$ is the distance between the $j$ th monitoring station in the $i$ th tributary and the nearest water intake in the downstream area $(\mathrm{km})$; and $S$ is the subset of those candidate stations that are located in the upper stream of the water intakes (no unit).

The fuzzy membership values associated with different objectives interweaved could be addressed by several ways, such as additive form, multiplicative form, weighted mean, weighted product, and geometric mean, depending upon the real implications in the decision analysis. It has been verified that the use of multiple aspiration levels to address the achievement of different objectives consists of several merits as opposed to using only a common aspiration level for all objectives (Chang et al., 1997; Chen and Chang, 1998). With both compensatory and competitive mechanism, such an approach has been proved effective to reduce the possible exaggeration by any individual aspiration level with extremely low value during the trade-off process (Chang et al., 1997; Chen and Chang, 1998). Hence, aspiration levels of $\mu_{Z_{1}}, \mu_{Z_{2}}, \mu_{Z_{3}}, \mu_{Z_{4}}$ and $\mu_{Z_{5}}$ are defined as membership values corresponding to five membership functions, respectively, and the resultant objective function with respect to the max-min rationale in the fuzzy mutiobjective programming model should be defined as a function in terms of a series of weighted aspiration level $\left(\mu_{Z_{i}}\right)$ associated with five objectives. The choice of those decision weights may require an independent survey within the group of decision makers. In general, we could assume that all the objectives are equally important if no special concerns are raised in the decision arena. Thus, the fuzzy objective function may be defined as follow:

$\operatorname{Max} \mu_{Z_{1}}+\mu_{Z_{2}}+\mu_{Z_{3}}+\mu_{Z_{4}}+\mu_{Z_{5}}$. 


\subsubsection{Constraint Set}

Expect for the fuzzy goal constraints, which are formulated based on the fuzzy optimization mechanism, additional constraints consist of the budget constraint, detection sensitivity constraint, equity constraint, water quality constraint for water intakes, and the non-negativity constraint. The formulation of the constraint set is illustrated as follow:

\section{Fuzzy Goal Constraint}

The following constraints are defined according to the membership functions associated with those fuzzy planning objectives. They perform fundamental interactions with each objective in the screening procedure.

$$
\begin{aligned}
& Z_{1} \geq L_{1}+\mu_{Z_{1}}\left(U_{1}-L_{1}\right) \\
& Z_{2} \geq L_{2}+\mu_{Z_{2}}\left(U_{2}-L_{2}\right) \\
& Z_{3} \geq L_{3}+\mu_{Z_{3}}\left(U_{3}-L_{3}\right) \\
& Z_{4} \geq L_{4}+\mu_{Z_{4}}\left(U_{4}-L_{4}\right) \\
& Z_{5} \geq L_{5}+\mu_{Z_{5}}\left(U_{5}-L_{5}\right)
\end{aligned}
$$

in which $U_{1}, U_{2}, U_{3}, U_{4}$, and $U_{5}$ are the upper bound of tolerance interval in each fuzzy membership function, respectively; and $L_{1}, L_{2}, L_{3}, L_{4}$, and $L_{5}$ are the lower bound of tolerance interval in each fuzzy membership function, respectively.

\section{Budget Constraint}

This implies the total number of monitoring stations included in the alternative should be less than an upper bound to reflect budget limitation.

$$
\sum_{i=1}^{p} \sum_{j=1}^{q_{i}} Y_{i j} \leq M, \quad \forall i, j,
$$

in which $M$ is the upper bound of the total number of monitoring stations (no unit).

\section{Detection Sensitivity Constraint}

This implies the half-life distance overlapped between each pair of adjacent monitoring stations should be minimized as possible as we can. The coordinate system is defined as a one-dimensional system starting from the estuary location to the headwater (i.e., at the farthest location of the upper stream area). Figure 2 illustrates the technical settings of such coordinate system. In other words, the information of 'effectiveness of coverage' from a spatial sense considered for each monitoring station must be addressed by a representative aggregate index in relation to the half-life distance of all constitutes of concern. It needs several external runs via 


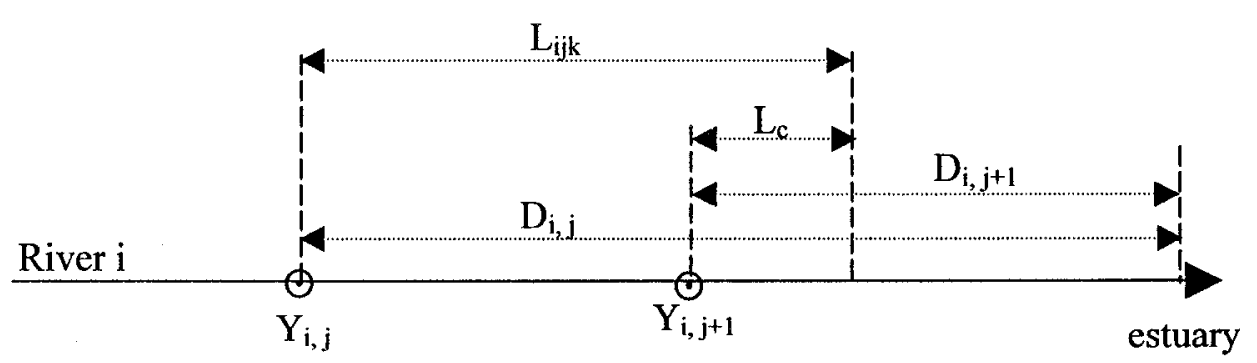

$\mathrm{Y}_{\mathrm{i}, \mathrm{j}}$ : the $\mathrm{j}^{\text {th }}$ candidate site located at the $\mathrm{i}^{\text {th }}$ tributary

$D_{i j}$ : the distance between the $j^{\text {th }}$ monitoring station located at the $i^{\text {th }}$ tributary and the reference point of estuary location $(\mathrm{km})$

$\mathrm{L}_{\mathrm{ijk}}$ : the half-life distance associated with candidate site $(\mathrm{km})$

$\mathrm{L}_{\mathrm{c}}=$ limitation of the overlapped influential distance allowed in this systems analysis $(\mathrm{km})$

Figure 2. Coordinate system diagram used in this study.

simulation analysis to illustrate how far the half-life distance of each monitoring station is with respect to all pollutants of concern and to aid in deriving the information of 'effectiveness of coverage'. Preference or emphasis can be assigned to a specific monitoring station or pollutant based on the value of $w_{i j k}$ in the equation.

$$
Y_{i, j+1} D_{i, j+1}-Y_{i j}\left[D_{i j}-\sum_{k=1}^{r}\left(w_{i j k} L_{i j k}\right)\right]<L_{c}, \quad \forall i, j,
$$

in which $D_{i j}$ is the geographical distance between the $j$ th monitoring station located at the $i$ th tributary and the reference point at the estuary area $(\mathrm{km})$; and $L_{c}$ is the limitation of the overlapped half-life distance allowed in this systems analysis $(\mathrm{km})$. Note that the subscript $j$ is defined for each candidate site sequentially from headwater to estuary region.

\section{Equity Constraint}

This suggests that each tributary in the river basin must at least have one monitoring station to be included in any alternative from an equity sense.

$$
\sum_{j=1}^{q_{i}} Y_{i j} \geq 1, \quad \forall \quad i
$$




\section{Protection of Water Intakes Constraint}

It means that each potable water intake must have at least one monitoring station to be located no more than $25 \mathrm{~km}$ within its upper stream area.

$$
\sum_{j \in S} Y_{i j, m} \geq 1, \quad \forall i, m,
$$

in which $Y_{i j, m}$ represents a binary variable whose value is 1 if the $j$ th monitoring station that is located at the upper stream area within $25 \mathrm{~km}$ is selected for the monitoring of $m$ th potable water intake in the $i$ th tributary; 0 otherwise.

\section{Non-negativity Constraint}

All decision variables (i.e., $Y_{i j}$ ) must be defined as non-negative and binary variables.

\section{Case Study}

\subsection{BACKGROUND INFORMATION}

The Kao-Ping River flows through approximately $140 \mathrm{~km}$ and drains toward the south part of Taiwan Strait. With an area of $3256 \mathrm{~km}^{2}$, the main stream of the Kao-Ping River originates from four small tributaries: Chi-San River, Liao-Nung River, Cho-Kou River, and Ai-Liao River. From the confluence to the union with those tributaries the river carries the name Kao-Ping River. The water year in a hydrological sense can be divided into wet season and dry season. The wet season generally covers the time period from May to October, and the remaining time period is the dry season. Although the mean annual rainfall in this river basin is close to $3000 \mathrm{~mm}$, over $90 \%$ of which appears in the wet season. The period of high flow rate in the stream usually occurs in late spring and summer due to the impacts of monsoon and typhoon. During the monsoon period, the Kao-Ping River flow increases to a level approximately 8 to 12 times higher than the dry season flow. Uneven rainfall over seasons has resulted in severe issue of water resources redistribution in the winter and earlier spring that inevitably requires building more reservoirs for water storage.

Although agriculture sector is always the largest user of water, the latest development of three large-scale industrial complexes in the adjacent Tseng-Wen River system requires more water to be diverted from the upper stream area of the Kao-Ping River in the wet season. The efforts of shipping water to meet industrial requirements will therefore increase substantially. Not only the new water demand from such an industrial development plan but also the rising population and the increase of living standard would make the ultimate needs of water resources continue to grow over time. The idea of a conjunctive operation of those weirs and reservoirs in both the Kao-Ping and Tseng-Wen River systems has been putting 
into practice since 1990. Such a water resources management program inevitably results in potential impact to the water quality in the downstream areas of the KaoPing River system. Water quality monitoring and assessment, therefore, plays an important role in public decision-making.

In recent years, due to severe pollution of river systems in South Taiwan, the effort of river basin planning has been evolved from the conservation of water resources toward the implementation of total maximum daily load (TMDL) program. The Kao-Ping River Basin, being the most active stock farming and industrialized area in Taiwan, exhibits a distinctive complexity in water quality management. It has a long history of higher biochemical oxygen demand (BOD) and amonianitrogen $\left(\mathrm{NH}_{3}-\mathrm{N}\right)$ due to inadequate disposal of manure from stock farming and domestic wastewater effluents. Figure 3 illustrates the waste load distribution and its pollution impact on water quality spatially. The downstream area of the KaoPing River, however, has long been served as potable water sources for the largest industrial city - Kaohsiung - for over decades in Taiwan. The needs for a systematic assessment to explore the possible expansion strategy of monitoring network in the Kao-Ping River Basin motivate such a decision analysis.

\subsection{Simulation ANALysis}

\subsubsection{Water Quality Survey}

To gain a deeper understanding of the water quality condition in the river reaches, a large-scale sampling campaign was carried out during dry and wet seasons respectively during the time periods of August 1998 and February 1999 (Ning et al., 2001). Each of the two sampling programs consists of a $96 \mathrm{hr}$ survey. Sampling sites cover the spots from headwater to estuary location. There are a total of fortysix stations including twenty-seven stations along the main stem of the river, seven of them near the estuary area, and the rest of them close to the exits of local drainage system along major tributaries. All field measurements were performed using portable meters. Temperature, $\mathrm{pH}$, and conductivity readings were taken in the field concurrently with the DO samples, and the rest of chemical analyses were performed in the laboratory.

\subsubsection{Calibration and Verification}

The application of QUAL2E model must be in conjunction with a rigorous field sampling and laboratory measurement program to identify the magnitude of model parameters and then to make an initial prediction for ensuring the forecasting accuracy. In the modeling analysis, the total study length of 170 River Kilometers in the Kao-Ping River system was discretized into 9 river reaches that consist of 85 computational elements. The measured stream flows in dry and wet seasons and the river geometry, provided by the Water Resources Bureau (Taiwan), were utilized as the essential hydraulic information to support the subsequent modeling practice. After achieving the field and laboratory measurements through a rigorous 


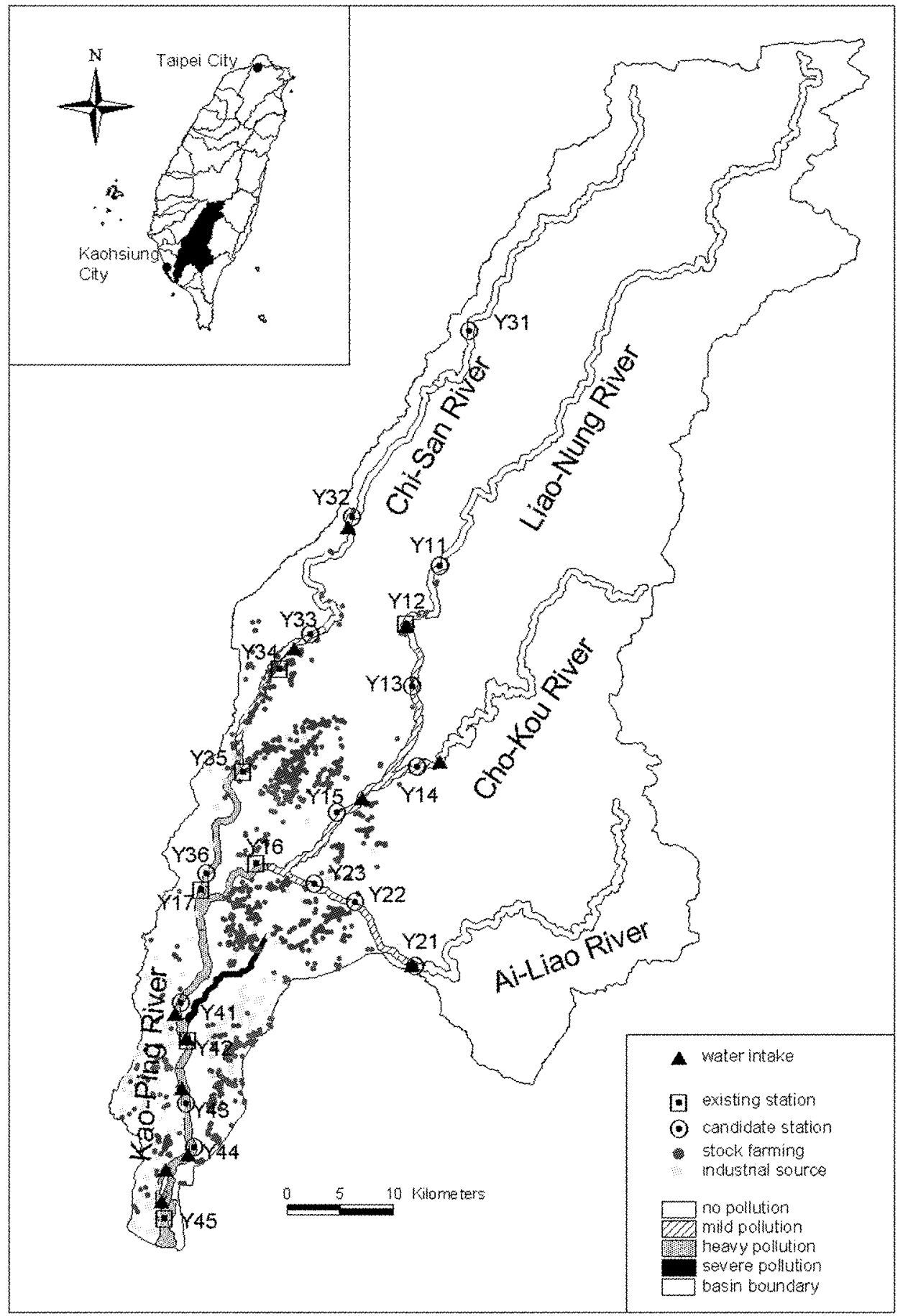

Figure 3. The pollution source distribution at present in the Kao-Ping River basin. 
quality assurance and quality control procedure, environmental database can then be integrated with hydraulic database and applied for model calibration and validation. In this study, QUAL2E has to be calibrated based on one set of observed data collected in the dry season and subsequently validated with an another set of observed data obtained in the wet season. The research finding shows a good match between computed and measured values, which may guarantee the accuracy in the prediction of half-life distance in the optimization analysis (Ning et al., 2001).

\subsubsection{Simulation Analysis}

A well calibrated and verificated model can then be used to predict the water quality levels at those candidate stations where there is not any monitoring record and the half-life distance required for optimization analysis. By assigning a unitary input concentration of pollutant at the location of each candidate site, repeated runs for all candidate sites may aid in acquiring the matrix of half-life distance in a river system.

\subsection{OPTIMIZATION ANALYSIS}

\subsubsection{Input Data Acquirement}

In this study twenty-one candidate monitoring stations were identified in the river system in which seven of them are the current ones. Figure 3 also indicates where those candidate and existing monitoring stations are. Most of the existing stations are located in the downstream area close to higher populated region. The use of geographical information system (GIS) to help determine the essential parameters is viewed as an indispensable tool in this optimization analysis. With the aid of the QUAL2E simulation outputs, the parameter of half-life distance $\left(L_{i j k}\right)$ representing the required length of river reach for a decay of half concentration of a pollutant of concern with respect to each candidate site may become predictable. Such information is beneficial for use in the formulation of the third objective function and the third constraint. In addition, the situation of attainment or non-attainment of water quality in the Kao-Ping River system required for defining the first objective function could be acquired directly from the sampling and analysis program. The spatial analysis, which is embedded as one of the basic functions of ArcView ${ }^{\circledR}$ GIS software package, may be helpful for the determination of population density resided in a radius of $10 \mathrm{~km}$ around each candidate site in this river system. GIS is also useful for measuring the geographical distance between each candidate site and the other reference points, such as the estuary location or water intakes. The spatial information associated with three modes of water utilization officially classified must also be included in the model formulation.

\subsubsection{Membership Function Preparation}

Fuzzy expressions that explicitly address the uncertainties in decision analysis with respect to five planning objectives were applied for generating a set of more 
robust and flexible alternatives in the solution procedure. Figure 4 illustrates the membership functions used in this study in which the tolerance interval of each membership function was determined in terms of possible variations of each objective function values in the pay-off table. The average of maximum and minimum values associated with each objective function in the pay-off table was selected as the tolerance interval of membership function. However, twenty percent above or below that value was used as a basis for sensitivity analysis.

\subsubsection{Planning Scenarios Arrangement}

Illegal spill in this river system receives wide attention, which reflects the needs of monitoring at all water intakes. Thus, the inclusion or exclusion of such consideration helps initialize three planning scenarios (see Table I). The first scenario temporarily excludes the consideration of water intakes protection in both objective function and constraint set. However, the fifth objective function and the fifth constraint, both emphasizing the importance of the protection of water intakes with different strength, could be exclusively selected in the planning scenario. While the second scenario specially considers the fifth objective function only, the third scenario uniquely retains the fifth constraint without taking the fifth objective function into account. Moreover, background information can be arranged in each planning scenario with different technical settings that may further explore the parameter sensitivity. They can address the conditions of whether the existing stations are included in the practice and whether the budget constraint is critical or not. If the budget is not sensitive in governmental agency, 15 instead of 10 may be assigned for regulating the total number of stations in the river system of concern. However, spatial priority that was designed to illustrate the preference order of each candidate site in the way to expand the entire monitoring network stepwise may become predictable and applicable in the optimization analysis if necessary.

\section{Results and Discussions}

The optimal expansion strategy of water quality monitoring network based on various technical settings can then be realized as the optimization model was solved by the software package LINDO $^{\circledR}$. Table II delineates the entire optimization outputs. In this decision matrix, the total number of monitoring stations selected may vary from 10 to 15 depending on the actual planning scenario designed for linking various objectives and constraints. When the total number of stations is limited to 15 , the research findings indicate that the longer the overlapped halflife distance is allowed, the more the candidate stations are selected. This is true no matter whether the existing stations have to be retained or not. If the existing stations are retained and the total number of stations is limited to 15, a siting pattern with slightly different structure could occur in the downstream area. This can be evidenced by cases 1(e), 2(e), and 3(e). However, the fifth constraint is relatively 


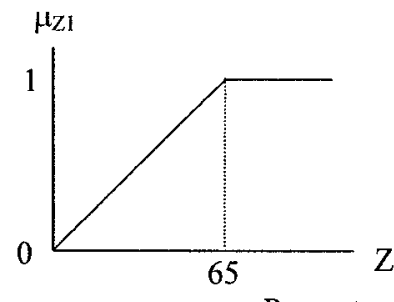

$$
\mu_{Z 1}= \begin{cases}0 & \text { if } Z_{1} \leq 0 \\ \frac{1}{65} Z_{1} & \text { if } 0<Z_{1}<65 \\ 1 & \text { if } Z_{1} \geq 65\end{cases}
$$

Percentage of non-attainment

$\mu_{\mathrm{Z2}} \quad$ time period (\%)

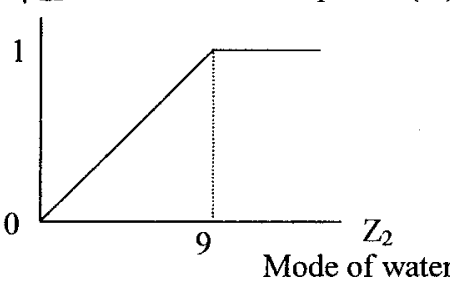

$$
\mu_{Z 2}= \begin{cases}0 & \text { if } Z_{2} \leq 0 \\ \frac{1}{9} Z_{2} & \text { if } 0<Z_{2}<9 \\ 1 & \text { if } Z_{2} \geq 9\end{cases}
$$

$\mu_{\mathrm{Z3}} \quad$ utilization (no unit)

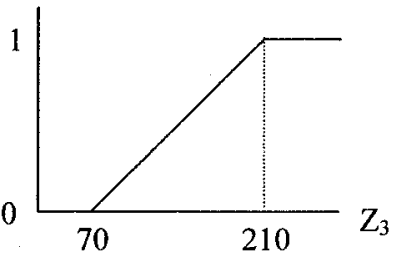

$$
\mu_{\mathrm{Z} 3}=\left\{\begin{array}{cl}
0 & \text { if } Z_{3} \leq 70 \\
\frac{Z_{3}-70}{140} & \text { if } 70<Z_{3}<210 \\
1 & \text { if } Z_{3} \geq 210
\end{array}\right.
$$

Distance required for a decay of half concentration of

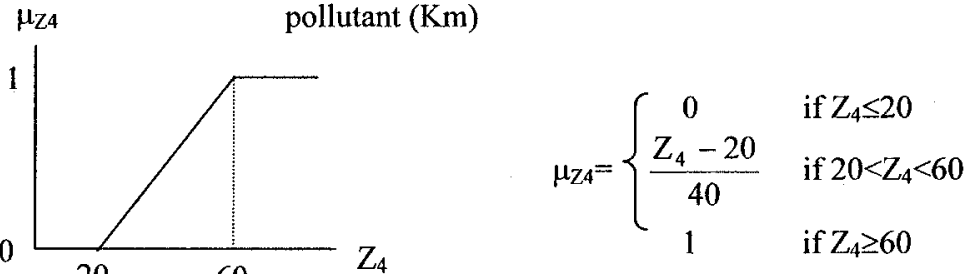

Population covered within the $10 \mathrm{Km}$ of monitoring station

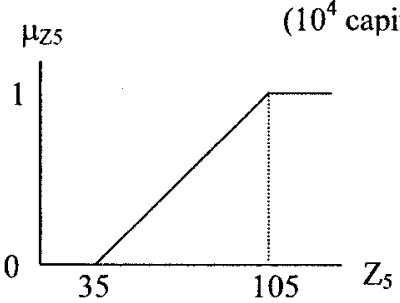

$$
\mu_{\mathrm{Z5}}=\left\{\begin{array}{cl}
0 & \text { if } Z_{5} \leq 35 \\
\frac{Z_{5}-35}{70} & \text { if } 30<Z_{5}<105 \\
1 & \text { if } Z_{5} \geq 105
\end{array}\right.
$$

The inverse of distance between candidate monitoring station and water intake $(\mathrm{Km})$

Figure 4. Definition of membership functions. 
TABLE I

The planning scenarios in this study

\begin{tabular}{lcccc}
\hline & & Scenario 1 & Scenario 2 & Scenario 3 \\
\hline Objective function & 1 & $\mathrm{X}$ & $\mathrm{X}$ & $\mathrm{X}$ \\
& 2 & $\mathrm{X}$ & $\mathrm{X}$ & $\mathrm{X}$ \\
& 3 & $\mathrm{X}$ & $\mathrm{X}$ & $\mathrm{X}$ \\
& 4 & $\mathrm{X}$ & $\mathrm{X}$ & $\mathrm{X}$ \\
Constraint set & 5 & & $\mathrm{X}$ & \\
& & & & \\
& 2 & $\mathrm{X}$ & $\mathrm{X}$ & $\mathrm{X}$ \\
& 3 & $\mathrm{X}$ & $\mathrm{X}$ & $\mathrm{X}$ \\
& 4 & $\mathrm{X}$ & $\mathrm{X}$ & $\mathrm{X}$ \\
& 5 & & & $\mathrm{X}$ \\
& 6 & $\mathrm{X}$ & $\mathrm{X}$ & $\mathrm{X}$ \\
\hline
\end{tabular}

sensitive in the optimization analysis such that both cases 3(a) and 3(b) cannot find compromise solutions. With different technical settings, the aspiration levels achieved in cases 2(d) and 2(e) are higher than the corresponding values in cases 3(d) and 3(e), respectively. It implies that using the constraint formula to achieve the goal of promoting the water quality monitoring for all water intakes is less powerful and attractive than using the objective function. Highest aspiration level (i.e., 5.0) appears in the case of 2(c) when five planning objectives are all included. When the overlapped half-life distance allowed increases up to $30 \mathrm{~km}$ between adjacent stations and the upper bound of the total number of stations remain unchanged in several cases, there is no much difference with regard to the optimal siting patterns in those expansion programs. Higher aspiration levels, as shown in cases 1(c), 2(c), and 3(c), reveal that the longer the overlapped half-life distance, the flexible the siting strategy and the larger the application potential.

Overall, retaining all existing stations in the modeling process would generally drive the optimal expansion strategy toward choosing those stations located at the middle stream and upper stream areas. This can be evidenced by these cases 1(e), 2(e) and 3(e). But one of the candidate stations, denoted by $\mathrm{Y}_{36}$, which belongs to the Chi-San River system, has never been selected as an appropriate one in the screening process. It is observed that conflict and compromise between five planning objectives are phenomenal. This is because we have come to realize that the second objective tries to emphasize the importance of conserving the higher water quality regions in the upper stream area but the fourth objective focuses on the protection of those nonattainment areas close to the estuary region where the population density is higher than the others. However, the first and the second objectives 


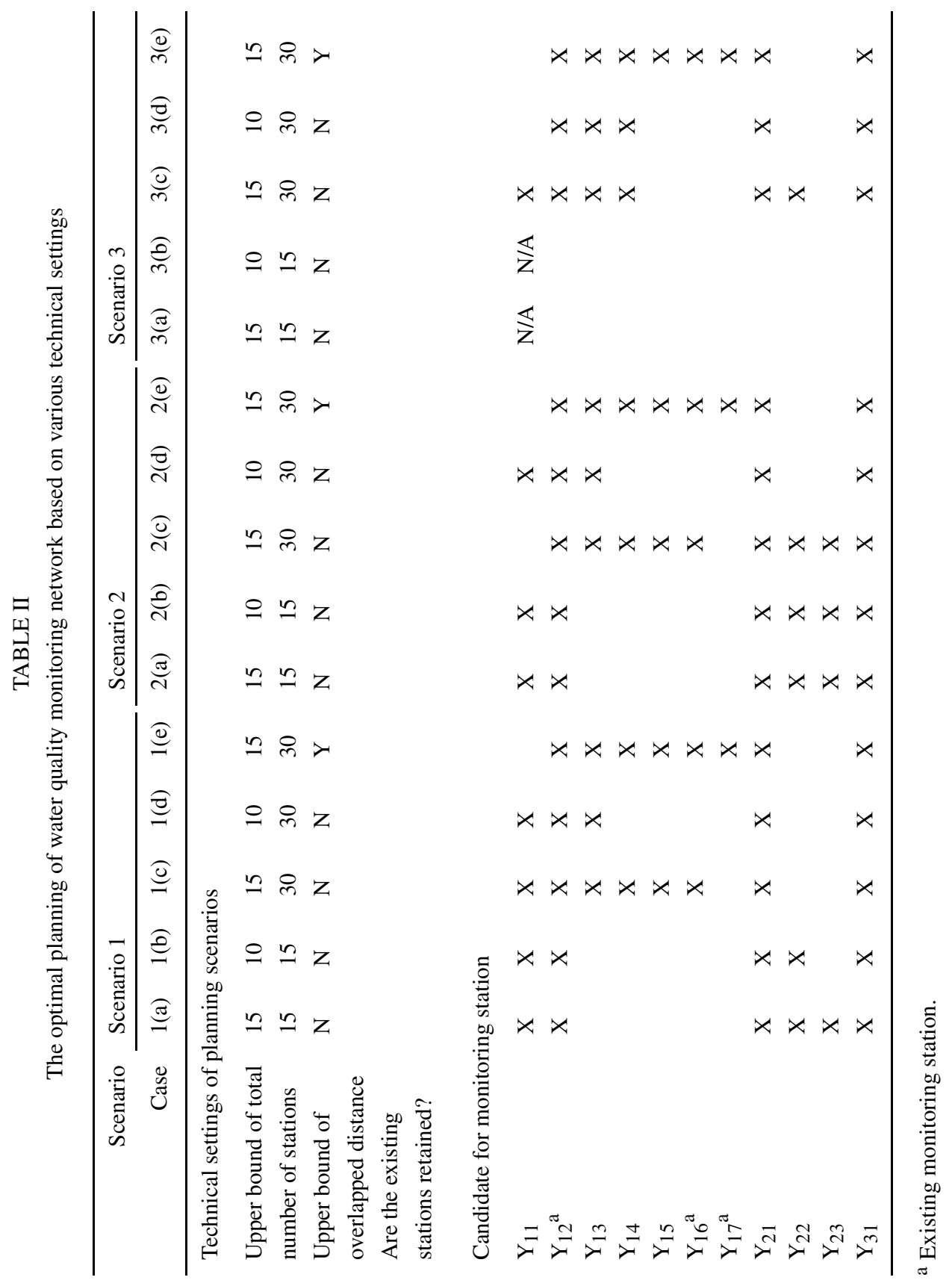




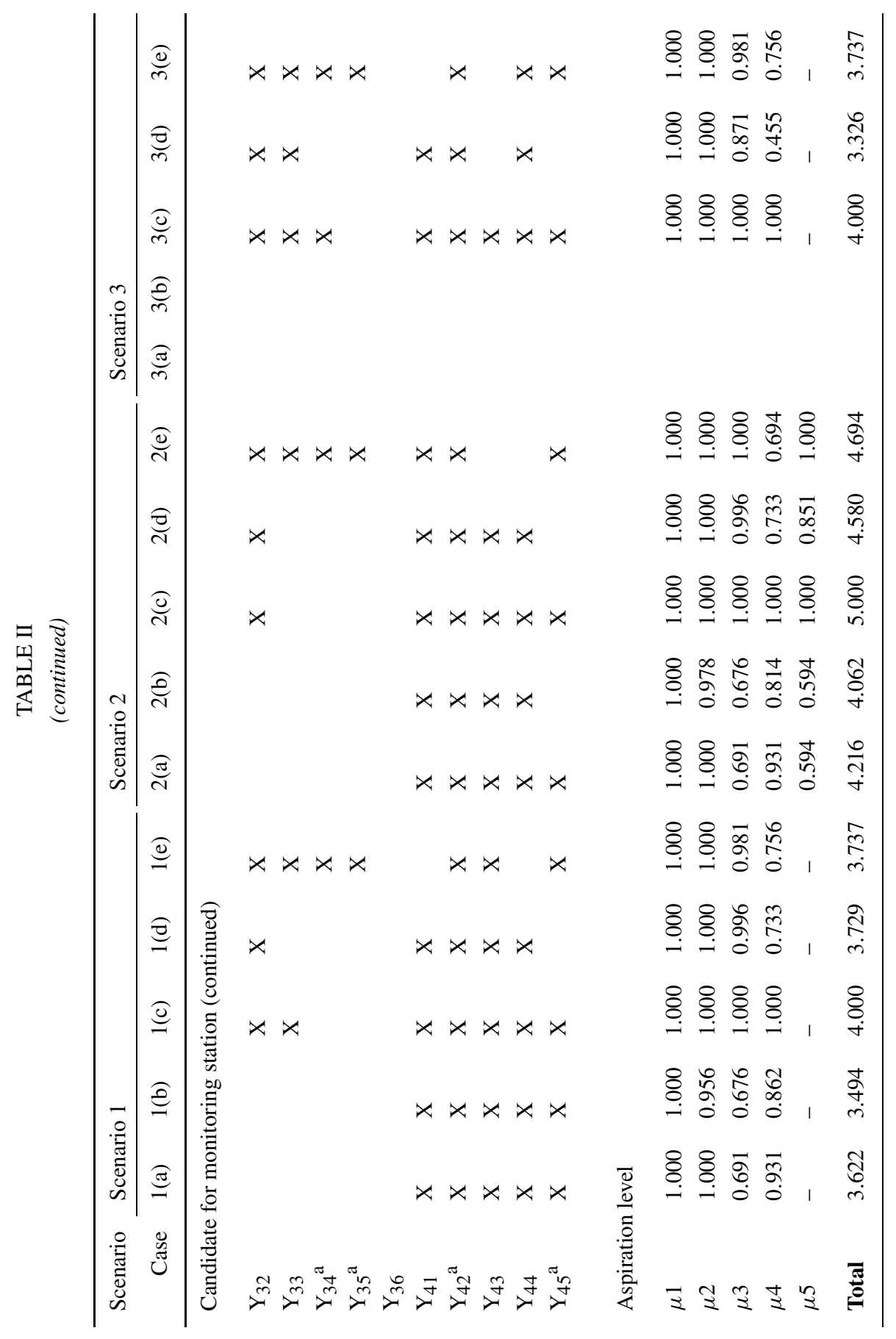


TABLE III

Spatial priority analysis for the optimal expansion program

\begin{tabular}{lllllllll}
\hline \multicolumn{10}{c}{ Preference order } \\
\cline { 2 - 8 } & 1 & 2 & 3 & 4 & 5 & 6 & 7 & 8 \\
\hline Candidate site & $\mathrm{Y}_{21}$ & $\mathrm{Y}_{32}$ & $\mathrm{Y}_{44}$ & $\mathrm{Y}_{43}$ & $\mathrm{Y}_{15}$ & $\mathrm{Y}_{11}$ & $\mathrm{Y}_{22}$ & $\mathrm{Y}_{23}$ \\
\hline
\end{tabular}

exhibit dominant impacts in the trade-off process, which can be characterized by their larger aspiration levels gained in the optimization steps. Nevertheless, many of the existing stations were finally excluded in the trade-off process. This implies the location pattern in the existing monitoring network did not conform to the optimum arrangement. With the needs of a fully applied regional TMDL program in the near future, final decision can then be made based on the suggestion in the case of 2(e) or 3(e). Figure 5 shows the suggested optimal expansion scheme based on the output of case 3(e). It assumes the budget limitation is not so sensitive that all the expansion work can be done at a time. If this is not the case, stepwise expansion has to be applied. Limiting the total number of stations by 1 in the constraint and fixing the successive selection by a sequential approach can find stepwise optimal expansion scheme. Table III lists the preference order of network expansion for decision maker once the expansion program is constrained critically by the budget and the governmental agency has to achieve the goals by a stepwise approach.

Risk involved in such decision analysis may arise from the subjective determination of tolerance interval in membership functions. A sensitivity analysis in relation to the predetermined tolerance intervals would be helpful to test the robustness of final optimal solution. The research findings clearly reveals that varying the tolerance intervals by $20 \%$ above or below the current values will not significantly alter the optimal siting patterns in most cases (see Table IV). This could end up with a conclusion that alternation of tolerance intervals by decision-makers in real world applications will not obviously change the final optimal expansion strategy of water quality monitoring network in this river system.

\section{Conclusion}

Planning a sound monitoring network in a river basin in response to the needs of regular water quality management mission on a continuous basis is a complex and challenging task. This analysis presents a state-of-the-art integration between simulation and optimization models. With the aid of QUAL2E or WASP model, it is capable of determining the environmental assimilative capacity along the river reaches in the first stage, and then conducting the optimization analysis to support the final assessment of optimal expansion alternatives of water quality monitoring 


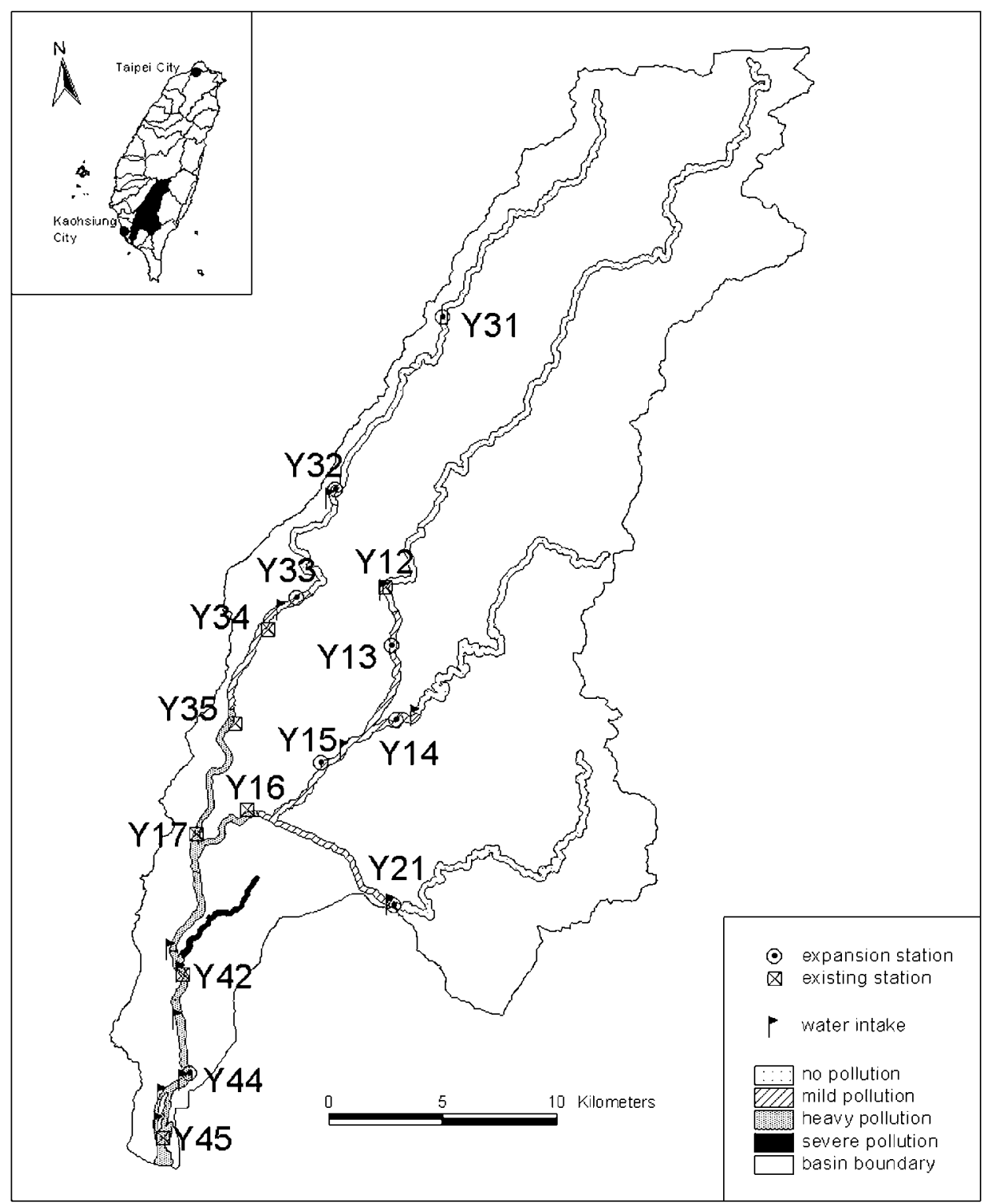

Figure 5. The optimal expansion strategy of water quality monitoring network in the Kao-Ping River system.

network in the second stage. In the way to make successful simulation runs and formulating the representative optimization model, GIS aids in performing the work of data archival, data analysis, and spatial analysis in the entire analytical framework. Fuzzy membership functions can be particularly designed to address the systematic uncertainties embedded in the multi-objective evaluation process. It helps delineate 
the planning objectives by a more realistic approach. This effort eventually leads to a successful screening, selection, and sequencing of optimal expansion alternatives in an existing water quality monitoring system in the Kao-ping River Basin, South Taiwan.

The emphasis of protecting all water intakes in this river system does provide a decision matrix. Scenarios with different technical settings may satisfy various needs in decision analysis. The upcoming TMDL program in the near future motivates final decision of the expansion profile to be made based on the suggestions in the case of 2(e) or 3(e). Spatial priority analysis clearly provides a stepwise choice of expansion sequence onwards based on a preference order of all candidate sites in this river system. The research findings also indicate that varying the ranges of tolerance intervals in the membership functions is not sensitive to the optimal expansion strategy. Overall, the germane insights embedded in both application challenge and system complexity where the water resources and water quality management systems have to be intimately linked together for meeting the goals of regional economic development were proved promising in decision analysis.

\section{Acknowledgement}

The authors acknowledge the helpful comments provided by anonymous referees in the reviewing process.

\section{References}

Bogardi, A., Bardossy, L. and Duckstein: 1983, 'Regional management of an aquifer for mining under fuzzy environmental objectives', Water Resour. Res. 19, 1394-1402.

Brown, L. C. and Barnwell, T. O.: 1987, The Enhanced Stream Water Quality Model QUAL2E and QUAL2E-UNCAS: Document and User Manual, EPA/600/3-87/007, U.S. Environmental Protection Agency, Environmental Research Laboratory, Athens, GA.

Beckers, C. V. and Chamberlain, S. G.: 1974, Design of Cost-effective Water Quality Surveillance Systems, U.S. EPA-600\5-74-404, Washington D.C., U.S.A.

Chang, N. B., Wen, C. G., Chen, Y. L. and Yong, Y. C.: 1996, 'Optimal planning of the reservoir watershed by grey fuzzy multi-objective programming (I): Theory', Water Res. 30(10), 23292334.

Chang, N. B., Wen, C. G., Chen, Y. L. and Yong, Y. C.: 1996, 'Optimal planning of the reservoir watershed by grey fuzzy multi-objective programming (II): Application', Water Res. 30(10), 2335-2340.

Chang, N. B., Wen, C. G. and Chen, Y. L.: 1997, 'A fuzzy multiobjective programming approach for optimal management of the reservoir watershed', Eur. J. Oper. Res. 99(2), 304-323.

Chang, N. B. and Tseng, C. C.: 1999, 'Optimal evaluation of expansion alternatives for existing air quality monitoring network by grey compromise programming', J. Environ. Manage. 56(1999), 61-77.

Chen, H. W. and Chang, N. B.: 1998, 'Water pollution control in the river basin by fuzzy genetic algorithm-based multiobjective programming modelling', Water. Sci. Technol. 37(3), 55-63. 
Claessen, F. A. M.: 1997, 'Comparing monitoring of surface and ground water systems', Eur. Water Pollut. Control 7(4), 27-35.

Cieniawski, S. E., Eheart, J. W. and Ranjithan, S.: 1995, 'Using genetic algorithms to solve a multiobjective ground-water monitoring problem', Water Resour. Res. 31(2), 399-409.

Dixon, W. and Chiswell, B.: 1996, 'Review of aquatic monitoring program design', Water Res. 30(9), 1935-1948.

Ellis, J. C.: 1989, Handbook on the Design and Interpretation of Monitoring Programs, Publication NS 29, Water Research Centre, Medmenham, England.

Esterby, S. R., El-Shaarawi, A. H. and Block, H. O.: 1992, 'Detection of water quality changes along a river system', Environ. Monit. Assess. 23, 219-242.

Feiring, B. R., Sastri, T. and Sim, L. S. M.: 1998, 'Stochastic programming model for water resource planning', Math. Comput. Model. 27(3), 1-8.

Groot, S. and Schilperoot, T.: 1983, 'Optimization of water quality monitoring networks', Water Sci. Technol. 16, 275-287.

Hudak, P. F., Loaiciga, H. A. and Marino, M. A.: 1995, 'Regional-scale ground-water quality monitoring via integer programming', J. Hydrol. 164, 153-170.

Harmancioglu, N. B. and Alpaslan, N.: 1992, 'Water quality monitoring network design: a problem of multi-objective decision marking', Water Resour. Bull. 28(1), 179-192.

Jousma, G. and Willems, W. J.: 1996, 'Ground-water monitoring networks', Eur. Water Pollut. Control 6(5), 52-62.

Kindler, J.: 1992, 'Rationalizing water requirements with aid of fuzzy allocation model', J. Water Res. Pl. - ASCE 118, 308-323.

Lo, S. L., Kao, J. T. and Wang, S. M.: 1996, 'Water quality monitoring network design of Keelung River, Northern Taiwan', Water Sci Technol. 34(1), 49-57.

Loftis, J. C., McBride, G. B. and Ellis, J. C.: 1991, 'Considerations for scale in water quality monitoring and data analysis', Water Resour. Res. 27(2), 255-264.

Loaiciga, H. A., Charbeneau, R. J., Everett, L. G., Fogg, G. E., Hobbs, B. F. and Rouhani, S.: 1992, 'Review of ground-water quality monitoring network design', J. Hydraul. Eng. - ASCE 118(1), $11-37$.

Lettenmaier, D. P., Anderson, D. E. and Brenner, R. N.: 1984, 'Consolidation of stream quality monitoring network', Water Resour. Bull. 20(4), 473-481.

Lettenmaier, D. P.: 1978, 'Design considerations for ambient stream quality monitoring', Water Resour. Bull. 14(4), 884-902.

Lee, Y. W., Dahab, M. F. and Bogardi, I.: 1994, 'Fuzzy decision making in ground water nitrate risk management', Water Resour. Bull. 117, 135-148.

Moore, S. F.: 1973, 'Estimation theory applications to design of water quality monitoring system', $J$. Hydraul. Div. - ASCE, 815-831.

Ning, S. K., Chang, Ni-Bin, Yang, L., Chen, H. W. and Hsu, H. Y.: 2001, 'Assessing pollution prevention program by QUAL2E simulation analysis for the Kao-Ping River Basin, Taiwan', J. Environ. Manage. 61(1), 61-76.

Skalski, J. R. and Mackenzie, D. H.: 1982, 'A design for aquatic monitoring programs', J. Environ. Manage. 14, 237-15.

Smith, D. G. and McBride, G. B.: 1990, 'New Zealand's national water quality monitoring network design and lst year's operation', Water Resour. Bull. 26(5), 767-775.

Sprull, T. D. and Candela L.: 1990, 'Two approaches to design of monitoring networks', Ground Water 28(3), 430.

Timmerman, J. G., Adriaanse, M., Breukel, R. M. A., Van Oirschot, M. C. M. and Ottens, J. J.: 1997, 'Guidelines for water quality monitoring and assessment of transboundary rivers', Eur. Water Pollut. Control 7(5), 21-30.

U.S. EPA: 2002, http://www.epa.gov/owow/monitoring/monintr.html. 
Van Belle, G. and Hughes, J. P.: 1983, 'Monitoring for water quality: Fixed stations verus intensive surveys', J. Water Pollut. Control Fed. 55(4). 400-404.

Wu, S. M., Huang, G. H. and Guo, H. C.: 1997, 'Interactive inexact-fuzzy approach for multiobjective planning of water resource systems', Water Sci. Technol. 36(5), 235-242.

Whitfeld, P. H.: 1988, 'Goals and data collection designs for water quality monitoring', Water Resour. Bull. 24(4), 775-780.

Ward, R. C.: 1979, 'Regulatory water quality monitoring: A systems perspective', Water Resour. Bull. 15(2), 369-380. 